Given the strides that have been made in understanding why organizations persistently refuse to 'learn' from mistakes, and the role of organizational interests and power in catastrophes, it is surprising that in their models, the authors assume that organizations will behave rationally, so that everything can be fixed in order to achieve high reliability. A long list of accident studies they do not cite challenges this assumption, most strikingly Scott Sagan's The Limits of Safety (Princeton University Press, 1993; for a review see Nature 367, 30;1994), and before that the work of Lee Clarke, Diane Vaughan, Kai Erikson, J. S. Kroll-Smith, Paul Shrivastava and many others.

To be fair, there are references to the "bounded rationality" school of organizational analysis (James March) and to James Reason who is sceptical about rational models. But examination of the five accidents reported in detail reveals that it is unlikely that any of those responsible would have behaved differently had they carefully studied this book. Accidents are rare; other problems and interests are far more pressing than pursuing the culmination of this book, the cumbersome "socio-technical failure minimizing systems model".

The puzzling thing about accidents and especially large catastrophes is that they are so few, given the enormous number of systems operating without the requisite structures so exhaustively enumerated here. It is hard to have just the right combination of system failures and environmental conditions to kill a lot of people in one blow. For this reason, countless risky systems successfully skirt disaster, skimping on safety and putting other interests first, while regulators fuss. The few that do experience "negative synergy", such as those described in this book, provide only obvious lessons that the rest continue to ignore for quite understandable if often deplorable reasons. Disturbingly, we have little more to say about the matter.

Charles Perrow is in the Institution for Social and Policy Studies, Yale University, Box 1965, New Haven, Connecticut 06520 1965, USA, and author of Normal Accidents (BasicBooks, 1984).

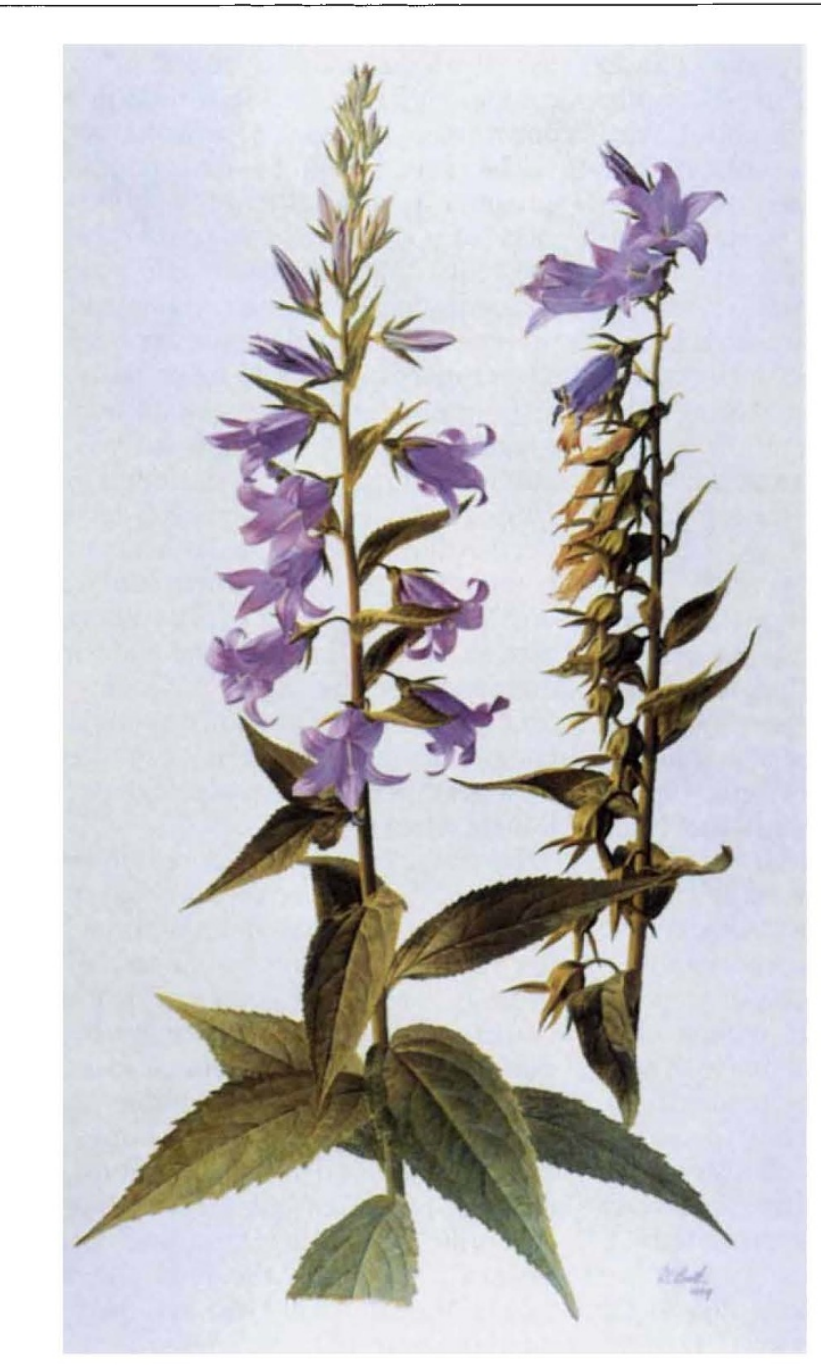

Giant bellflower (Campanula latifolia). Oil painting by Raymond Booth (1969). The picture is reproduced in The Art of Botanicalllilustration by Wilfrid Blunt and William T.Stearn (Antique Collectors' Club, £29.95). First published in 1950, this classic work has been long out of print. Now substantially revised and enlarged, the new edition contains 126 colour plates and 140 black-and-white illustrations, and aims to provide a comprehensive and critical survey, spanning more than 3,000 years, of the portrayal of plants.

\section{The new geology}

\section{Andrew Goudie}

Geology and Environment in Britain and Ireland. By Nigel Woodcock. UCL Press: 1994. Pp. 184. £14.95 (pbk).

THIS slim volume, aimed at first-year undergraduates and college students, attempts to outline the ways in which geology relates to human society, and to illustrate this with examples from the British Isles. It covers geological influences on society (landscape, human geography and hazards); Earth resources for society (land, water, construction materials, minerals, coal and peat, petroleum and energy); and human impact on Earth (resource extraction, engineering geology, and pollution).

This is an awful lot of material to compress into such a small compass. As a result, nothing is explored in detail and the style is compact to the point of being terse. On the other hand, the amount and style of illustrative material is first class, and I found myself spending far more time analysing the figures than in absorbing the text. The illustrations have all been specially drawn to a particular style and are refreshingly clear and simple yet informative. Students will also benefit from the guides to further reading, which are placed at the end of each chapter and include references to the geographical as well as the environmental literature.

The publisher makes certain claims for the book in terms of the changing nature of geology: "This book is published at a pivotal point in the history of geology. Scientists who, for a century and a half, have been preoccupied with finding earth resources are increasingly being asked where on earth to dispose of the effluents from using them ... [the] final chapter breaks new ground in opening a debate on the ethical basis of applied geology - a debate which is needed to steer the subject into the 21st century."

Indeed, the author himself is somewhat damning about the level of environmental concern shown by geologists, which for the first half of this century is described as being "so thin that it can be recognized only in retrospect. Even the more recent growth in anxiety over human impacts on the environment has yet to filter deeply through the geological profession." The plea is that geologists should take a more holistic and systems-oriented approach to the environment. Following Woodcock's example they should read more geography.

Andrew Goudie is in the School of Geography, University of Oxford, Oxford OX1 3TB, UK.

NATURE · VOL 370 • 25 AUGUST 1994 